\title{
Socio-demographic determinants of Toxoplasma gondii seroprevalence in migrant workers of Peninsular Malaysia
}

Norhidayu Sahimin ${ }^{1}$, Yvonne A. L. Lim², Farnaza Ariffin ${ }^{3}$, Jerzy M. Behnke ${ }^{4}$, Maria-Gloria Basáñez ${ }^{5}$ Martin Walker ${ }^{6}$, John W. Lewis ${ }^{7}$, Rahmah Noordin ${ }^{8}$, Khairul Anuar Abdullah ${ }^{9}$ and Siti Nursheena Mohd Zain ${ }^{1 *}$ (D

\begin{abstract}
Background: The number of migrants working in Malaysia has increased sharply since the 1970's and there is concern that infectious diseases endemic in other (e.g. neighbouring) countries may be inadvertently imported. Compulsory medical screening prior to entering the workforce does not include parasitic infections such as toxoplasmosis. Therefore, this study aimed to evaluate the seroprevalence of $T$. gondii infection among migrant workers in Peninsular Malaysia by means of serosurveys conducted on a voluntary basis among low-skilled and semi-skilled workers from five working sectors, namely, manufacturing, food service, agriculture and plantation, construction and domestic work.
\end{abstract}

Methods: A total of 484 migrant workers originating from rural locations in neighbouring countries, namely, Indonesia $(n=247,51.0 \%)$, Nepal $(n=99,20.5 \%)$, Bangladesh $(n=72,14.9 \%)$, India $(n=52,10.7 \%)$ and Myanmar $(n=14,2.9 \%)$ were included in this study.

Results: The overall seroprevalence of T. gondii was $57.4 \%$ ( $n=278 ; 95 \% \mathrm{Cl}$ : $52.7-61.8 \%)$ with $52.9 \%(n=256$; $95 \%$ Cl: $48.4-57.2 \%)$ seropositive for anti-Toxoplasma lgG only, $0.8 \%(n=4 ; 95 \% \mathrm{Cl}$ : $0.2-1.7 \%)$ seropositive for anti-Toxoplasma IgM only and 3.7\% ( $n=18 ; 95 \% \mathrm{Cl}: 2.1-5.4 \%)$ seropositive with both IgG and IgM antibodies. All positive samples with both IgG and IgM antibodies showed high avidity (> 40\%), suggesting latent infection. Age (being older than 45 years), Nepalese nationality, manufacturing occupation, and being a newcomer in Malaysia (excepting domestic work) were positively and statistically significantly associated with seroprevalence $(P<0.05)$.

Conclusions: The results of this study suggest that better promotion of knowledge about parasite transmission is required for both migrant workers and permanent residents in Malaysia. Efforts should be made to encourage improved personal hygiene before consumption of food and fluids, thorough cooking of meat and better disposal of feline excreta from domestic pets.

Keywords: Toxoplasma gondii, Migrant workers, Seroprevalence, Socio-demographic factors

\section{Background}

Toxoplasma gondii is one of the most common protozoan parasites affecting up to one-third of the world's population [1-3]. Human infection may occur via ingestion of food or water contaminated with oocysts shed in the faeces of infected cats; consumption of undercooked or raw meat; consumption of raw oysters,

\footnotetext{
* Correspondence: nsheena@um.edu.my

${ }^{1}$ Institute of Biological Science, Faculty of Science, University of Malaya, Kuala Lumpur, Malaysia

Full list of author information is available at the end of the article
}

clams, or mussels containing tissue cysts [4-8]; exposure to contaminated soil through activities such as gardening or children playing in sandpits [9] and vertical transmission from mother to foetus $[10,11]$.

Toxoplasmosis in immunocompromised people may causes damage to the brain, eyes, or other organs and is associated with severe acute infection or with reactivation of past infection. Infections acquired during pregnancy may cause severe damage to the foetus [11]. In immunocompromised patients, reactivation of latent infection can cause life-threatening encephalitis $[2,12]$. 
In recent years, there have been also many attempts to link toxoplasmosis with schizophrenia and other mental health problems (such as bipolar disorder) [13-15]. Toxoplasma gondii has emerged as a prime candidate when investigating the relationship between infectious agents and schizophrenia; some individuals with adult toxoplasmosis develop psychotic symptoms [13].

The standard method for diagnosis is through serological testing, based on the detection of Toxoplasmaspecific immunoglobulin IgG and IgM antibodies in serum and this test is routinely implemented in many parts of the world [16-18]. The detection methods previously employed in Malaysia have included the indirect hemagglutination (IHA) test, Sabin Feldman dye test, indirect fluorescent antibody test [19] and the enzymelinked immunosorbent assay (ELISA) [20].

Over the years, the economy in Malaysia has transformed into an emerging multi-sector economy and since the 1970s, its economic vigour has been facilitated largely by imported migrant workers. The number of migrant workers arriving in Malaysia from neighbouring countries has grown exponentially and there is concern that diseases endemic in their countries may be inadvertently imported [21], despite compulsory medical screening prior to entering the workforce in Malaysia. However, pre-employment screening does not currently include screening for the presence of most parasitic infections, including toxoplasmosis. The infection could have substantial public health implications with regard to the productivity of the migrant labour force and its contribution to the Malaysian economy and well-being.

Previous studies have presented a mixed picture on the seroprevalence of $T$. gondi infection among migrant compared to indigenous workers in Malaysia. Chan et al. [21] reported up to $42 \%$ (138/336) positive for specific IgG while twenty mainly Indonesian plantation workers and workers in detention camps $(6 \%)$ were positive with IgM [21]. Chan et al. [22] also noted the high prevalence of T. gondii infection among local plantation workers (IgG: $n=89,44.9 \%$ ) compared to migrants $(n=171,34.1 \%)$. However, there was no statistically significant difference in the prevalence of raised IgM between migrant workers $(n=26,5.2 \%)$ and locals $(n=17,8.6 \%)$. Amal et al. [23] reported a lower rate of raised specific IgG among workers $(n=16,18.8 \%)$ from the Indian subcontinent compared to locals $(n=89,44.9 \%)$ from the same plantation and detention camp. Similarly, another study also showed that just over a third (34.1\%, $171 / 501$ ) of migrant plantation workers and individuals in detention camps were IgG positive and 5.2\% (26/501) were IgM positive, with the highest infection rate among Nepalese workers (46.2\%) compared to other ethnic groups [24].

The current study was a component of a broader project aiming to assess the range and extent of parasitic infections brought into Malaysia by the migrant worker population. The study is motivated by the need to assess the health status of migrant workers originating from countries with low socioeconomic backgrounds, living in deprived environments with poor sanitation and low hygiene practices [25]. Here we report on seroprevalence of T. gondii among migrant workers in Malaysia and identify key factors associated with this infection.

\section{Methods \\ Study population and sample collection}

This study was carried out from September 2014 to August 2015 among informed, consenting low-skilled and semi-skilled workers from five working sectors in Peninsular Malaysia, namely: manufacturing; service; agriculture and plantation; construction, and domestic work. Questionnaires were distributed to participants to gather relevant information related to the study. An individual clinical interview with a questionnaire was conducted to collect information on sociodemographic data, migration history, environmental health, life-style habits (consumption of raw meat and vegetables), recent illness and occupational health and safety. The interview process was performed through an interpreter for those migrant workers who had difficulty understanding the Malay (national) and English languages. All participants were fully informed of the nature of the study and completed the consent forms.

After consent was obtained and the questionnaire answered, approximately $5 \mathrm{ml}$ of venous blood was drawn into a plain tube (without anticoagulant) by trained medical assistants and nurses using disposable syringes and needles. The blood samples were transported to the Parasitology Laboratory, Institute of Biological Science, Faculty of Science, University of Malaya. Blood samples were spun at $1,500 \times g$ for $10 \mathrm{~min}$ and the serum samples were kept in $-20{ }^{\circ} \mathrm{C}$ until use.

\section{Detection of immunoglobulin $\mathrm{G}$ and $\mathrm{M}$ antibodies to T. gondii}

Screening for anti-T. gondii antibodies was performed using enzyme-linked immunosorbent assay (ELISA) commercial kits for immunoglobulin G (IgG) and M (IgM) (Trinity Biotech Captia ${ }^{\mathrm{TM}}$, New York, USA) in accordance with the manufacturer's instructions. For the IgG assay, positive results were defined as $\geq 1.23 \mathrm{IU} / \mathrm{ml}$, indicating latent or pre-existing Toxoplasma infection. Positive results for IgM assays were also defined as $\geq 1.23 \mathrm{IU} / \mathrm{ml}$, indicating recent infection. All samples that were both IgG-positive and IgM-positive were tested using an IgG avidity assay (IgG; NovaLisa, Dietzenbach, Germany) according to the manufacturer's instructions. Toxoplasma antibodies with high avidity (> 40\%) indicate latent 
infection, while Toxoplasma antibodies with low avidity $(\leq 40 \%)$ indicate a probable acute or recent infection.

\section{Data analysis}

Prevalence estimates (percentage of participants infected) are shown with 95\% confidence intervals (CI) calculated using the method described by Rohlf \& Sokal (1995) [26]. Prevalence was analyzed using maximum likelihood techniques based on log linear analysis of contingency tables using the software package SPSS (Version 22), in three steps. First, full factorial models were fitted including the following 'intrinsic' factors: sex (2 levels, males and females), age ( 5 age classes comprising those $<25$ years old, 25-34 years old, 35-44 years old, 45-54 years old and those $>54$ years), nationality ( 5 countries, Bangladesh, India, Indonesia, Myanmar and Nepal) and immune status, which was considered as a binary factor (presence/absence of antiToxoplasma antibodies). For each level of analysis in turn, beginning with the most complex model, involving all possible main effects and interactions, those combinations that did not contribute significantly to explaining variation in the data were eliminated in a stepwise fashion beginning with the highest-level interaction (backward selection procedure in SPSS). A minimum sufficient model was then obtained, for which the likelihood ratio of the chi-square $\left(\chi^{2}\right)$ statistic was not significant, indicating that the model was sufficient in explaining the data. The importance of each term (i.e. interactions involving infection) in the final model was assessed by the probability that its exclusion would alter the model significantly and those values relating to interactions that included presence/absence of infection-specific antibodies (as described above) are given in the text.

Models were then fitted including the following 'extrinsic' factors: employment sector (5 sectors: construction, manufacture, plantation, food service and domestic), years of residence in Malaysia ( 2 categories: less than 1 year (year 1) and more than 1 year (year 2)), accommodation (3 types: hostel, construction site and own/rented home) and education (4 levels: primary school, secondary school, university and no formal schooling) and infection. Finally, in a third step, models were fitted comprising only the intrinsic and extrinsic factors that had been found to be statistically significantly associated with infection status as measured by presence of IgG/IgM.

Where relevant, we also fitted in turn models with just each factor and infection status, in order to resolve/clarify complex interactions that could not be simplified by the backward selection procedure. We have also provided in the tables the probability values from these models.

\section{Results}

Socio-demographic characteristics

A total of 484 migrant workers in Malaysia were included in this study originating from rural areas in neighbouring countries, namely: Indonesia $(n=247,51.0 \%) ;$ Nepal $(n=99,20.5 \%)$; Bangladesh $(n=72,14.9 \%) ;$ India $(n=52$, $10.7 \%)$, and Myanmar $(n=14,2.9 \%)$. Slightly over three quarters $(n=375,77.5 \%)$ were men, and the rest $(n=109$, $22.5 \%)$ women. Most were between the ages of 25 and 34 years $(n=183,37.8 \%)$, followed by less than 25 years $(n=142,29.3 \%)$, between 35 and 44 years $(n=111$, $22.9 \%)$, between 45 and 54 years $(n=35,7.2 \%)$ and greater than 54 years $(n=13,2.7 \%)$. According to the working sectors, the majority of volunteers were from the food service sector $(n=115,23.8 \%)$, followed by domestic $(n=106,21.9 \%)$, plantation $(n=102,21.1 \%)$, manufacturing $(n=93,19.2 \%)$ and construction $(n=68,14.0 \%)$ sectors. Most participants had at least a primary level of education $(n=228,47.1 \%)$ followed by high school $(n=201,41.5 \%)$ and higher (university) level $(n=10$, $2.1 \%)$, while $n=45$ participants $(9.3 \%)$ had not received any formal education.

\section{Seroprevalence of $T$. gondii}

The overall $T$. gondii seroprevalence among 484 migrant workers was $57.4 \%(n=278$; 95\% CI: $52.7-61.8 \%)$ with 52.9\% ( $n=256$; 95\% CI: 48.4-57.2\%) being seropositive for anti-Toxoplasma IgG only, $0.8 \%(n=4$; $95 \%$ CI: $0.2-$ 1.7\%) seropositive for anti-Toxoplasma IgM only and 3.7\% ( $n=18$; 95\% CI: $2.1-5.4 \%)$ seropositive for both IgG and IgM antibodies (Table 1). All positive samples with both IgG and IgM antibodies showed high avidity (> 40\%), suggesting latent infection.

\section{Intrinsic factors associated with the seroprevalence of T. gondii infections}

Seropositivity of $T$. gondii was analysed statistically in relation to sociodemographic factors. In the minimum sufficient model identified by the backwards stepwise selection procedure that included sex, age and nationality, only age $\left(\chi^{2}=11.989, d f=4, P=0.017\right)$ and nationality $\left(\chi^{2}=32.275, d f=4, \quad P \leq 0.001\right)$ were found to be statistically significantly associated with seropositivity for T. gondii IgG, independently (Table 2). Analyses of antiToxoplasma IgM and seropositivity based on a combination of both IgG and IgM antibodies, did not find any of the three intrinsic factors as statistically significantly affecting seroprevalence (Table 2).

Table 1 Seroprevalence of IgG and IgM antibodies to Toxoplasma gondii among 484 migrant workers using ELISA

\begin{tabular}{llcl}
\hline Antibodies & No. of seropositive & Seropositive (\%) & $95 \% \mathrm{Cl}(\%)$ \\
\hline $\operatorname{lgG}+$ & 257 & 53.0 & $48.3-57.7$ \\
$\lg \mathrm{M}+$ & 4 & 0.8 & $0.2-1.8$ \\
lgG+ IgM+ & 18 & 3.7 & $2.1-5.6$ \\
Total & 279 & 57.5 & $53.2-62.1$ \\
\hline
\end{tabular}

Abbreviation: $\mathrm{Cl}$ confidence interval 
Table 2 Seroprevalence of IgG and lgM antibodies to Toxoplasma gondii infections among migrant workers in Malaysia according to sex, age, nationality, employment sector, years of residence, accommodation and education

\begin{tabular}{|c|c|c|c|c|c|c|c|}
\hline \multirow[t]{2}{*}{ Factors } & & \multicolumn{2}{|l|}{$\lg G+$} & \multicolumn{2}{|l|}{$\lg M+$} & \multicolumn{2}{|l|}{$\operatorname{lgG}+\lg M+$} \\
\hline & & $\%(95 \% \mathrm{Cl})$ & $P$-value ${ }^{a}$ & $\%(95 \% \mathrm{Cl})$ & $P$-value & $\%(95 \% \mathrm{Cl})$ & $P$-value \\
\hline \multicolumn{8}{|l|}{ Intrinsic factors } \\
\hline \multirow[t]{2}{*}{ Sex } & Men $(n=375)$ & $55.7(50.5-60.8)$ & 0.469 & $4.8(2.9-7.5)$ & 0.610 & $3.7(2.1-6.2)$ & 0.975 \\
\hline & Women $(n=109)$ & $59.6(49.8-68.9)$ & & $3.7(1.0-9.1)$ & & $3.7(1.0-9.1)$ & \\
\hline \multirow[t]{5}{*}{ Age class (years)* } & $<25(n=142)$ & $59.2(50.6-67.3)$ & 0.045 & $3.5(1.2-8.0)$ & 0.732 & $3.5(1.2-8.0)$ & 0.853 \\
\hline & $25-34(n=183)$ & $51.4(43.9-58.8)$ & & $5.5(2.7-9.8)$ & & $3.8(1.6-7.7)$ & \\
\hline & $35-44(n=111)$ & $54.1(44.3-63.6)$ & & $4.5(1.5-10.2)$ & & $3.6(1.0-9.0)$ & \\
\hline & $45-54(n=35)$ & $74.3(56.7-87.5)$ & & $5.7(0.7-19.2)$ & & $5.7(0.7-19.2)$ & \\
\hline & $>55(n=13)$ & $76.9(46.2-95.0)$ & & $0.0(0.0-24.7)$ & & $0.0(0.0-24.7)$ & \\
\hline \multirow[t]{5}{*}{ Country of nationality* } & Indonesia $(n=247)$ & $58.3(51.9-64.5)$ & $<0.001$ & $5.3(2.8-8.8)$ & 0.448 & $5.3(2.8-8.8)$ & 0.325 \\
\hline & Bangladesh $(n=72)$ & $44.4(32.7-56.6)$ & & $2.8(0.3-9.7)$ & & $1.4(0.0-7.5)$ & \\
\hline & Myanmar $(n=14)$ & $28.6(8.4-58.1)$ & & $0.0(0.0-23.2)$ & & $0.0(0.0-23.2)$ & \\
\hline & India $(n=52)$ & $38.5(25.3-53.0)$ & & $1.9(0.0-10.3)$ & & $1.9(0.0-10.3)$ & \\
\hline & Nepal $(n=99)$ & $74.7(65.0-82.9)$ & & $6.1(2.3-12.7)$ & & $3.0(0.6-8.6)$ & \\
\hline \multicolumn{8}{|l|}{ Extrinsic factors } \\
\hline \multirow[t]{5}{*}{ Employment sector* } & Construction $(n=68)$ & $61.8(49.2-73.3)$ & $<0.001$ & $5.9(1.6-14.4)$ & 0.417 & $5.9(1.6-14.4)$ & 0.400 \\
\hline & Manufacturing $(n=93)$ & $74.2(64.1-82.7)$ & & $4.3(1.2-10.6)$ & & $2.2(0.3-7.6)$ & \\
\hline & Plantation $(n=102)$ & $44.1(34.3-54.3)$ & & $4.9(1.6-11.1)$ & & $3.9(1.1-9.7)$ & \\
\hline & Food service $(n=115)$ & $50.4(41.0-59.9)$ & & $1.7(0.2-6.1)$ & & $1.7(0.2-6.1)$ & \\
\hline & Domestic $(n=106)$ & $56.6(46.6-66.2)$ & & $6.6(2.7-13.1)$ & & $5.7(2.1-11.9)$ & \\
\hline \multirow[t]{2}{*}{ Years of residence* } & $<$ than 1 year $(n=180)$ & $65.0(57.6-71.9)$ & 0.004 & $6.7(3.5-11.4)$ & 0.091 & $5.6(2.7-10.0)$ & 0.107 \\
\hline & $>$ than 1 year $(n=304)$ & $51.6(45.9-57.4)$ & & $3.3(1.6-6.0)$ & & $2.6(1.1-5.1)$ & \\
\hline \multirow[t]{3}{*}{ Accommodation } & Own/rent house $(n=133)$ & $57.1(48.3-65.7)$ & 0.638 & $5.3(2.1-10.5)$ & 0.447 & $4.5(1.7-9.6)$ & 0.236 \\
\hline & Construction site $(n=53)$ & $62.3(47.9-75.2)$ & & $7.5(2.1-18.2)$ & & $7.5(2.1-18.2)$ & \\
\hline & Hostel by employer $(n=298)$ & $55.4(49.5-61.1)$ & & $3.7(1.9-6.5)$ & & $2.7(1.2-5.2)$ & \\
\hline \multirow[t]{4}{*}{ Education } & Primary $(n=228)$ & $54.4(47.7-61.0)$ & 0.114 & $4.8(2.4-8.5)$ & 0.674 & $3.9(1.8-7.4)$ & 0.572 \\
\hline & Secondary $(n=201)$ & $62.7(55.6-69.4)$ & & $4.0(1.7-7.7)$ & & $3.0(1.1-6.4)$ & \\
\hline & University $(n=10)$ & $50.0(18.7-81.3)$ & & $0.0(0.0-30.8)$ & & $0.0(0.0-30.8)$ & \\
\hline & No formal schooling $(n=45)$ & $42.2(27.7-57.8)$ & & $6.7(1.4-18.3)$ & & $6.7(1.4-18.3)$ & \\
\hline
\end{tabular}

${ }^{*} P<0.01$

${ }^{a} P$-values are based on each factor being fitted alone with presence/absence of antibodies and reflect the statistical significance of the variable in improving the fit of the model to the data. The results of the multifactorial models are described in the text

Abbreviation: $\mathrm{Cl}$ confidence interval

\section{Extrinsic factors associated with the seroprevalence of T. gondii infections}

Of the four extrinsic factors considered (employment sectors, years of residence in Malaysia, type of accommodation and level of education), only two factors were found to be statistically significantly associated with seropositivity of anti-Toxoplasma IgG in models that only included each factor in turn with presence of Toxoplasma IgG, i.e. employment sector $\left(\chi^{2}=21.306, d f\right.$ $=4, P \leq 0.001)$ and years of residence in Malaysia $\left(\chi^{2}\right.$ $=8.294, d f=1, P=0.004$ ) (Table 2). Seroprevalence was significantly and positively associated with those employed in the manufacturing industry and those recently arrived in Malaysia (the latter with the exception of domestic workers, in whom the converse negative association with years of employment was observed).

Finally, in a multifactorial model in which we fitted only the significant effects from the analyses of intrinsic and extrinsic factors (age, country of origin, years of residence and employment sector with Toxoplasma IgG seropositivity), three significant interactions were found, the strongest being employment sector interacting with years of residence and Toxoplasma IgG $\left(\chi^{2}=13.478\right.$, $d f=4, \quad P=0.009$ ). In four cases (employment sectors construction, manufacturing, plantation and the service industry), prevalence was higher in year 1 (72.7, 79.5, 48.6 
and $41.7 \%$, respectively) than in year $2(59.6,55.0,41.8$ and $43.6 \%$, respectively), indicating a reduction in infection between the two years, whilst for those in the domestic sector, prevalence increased from $41.7 \%$ in year 1 to $61.0 \%$ in year 2 . The other two interactions, years of residence interacting with age and Toxoplasma IgG $\left(\chi_{4}^{2}=9.603, P=0.048\right)$ and years of residence interacting with nationality and Toxoplasma $\operatorname{IgG}\left(\chi_{4}^{2}=9.628\right.$, $P=0.047$ ), were only marginally significant and thus were not explored further.

Models in which extrinsic factors were fitted with seropositivity of anti-Toxoplasma IgM, either alone or in combination with IgG did not identify any of factors as statistically significantly (Table 2).

\section{Discussion}

This study investigated the status of $T$. gondii infection among migrant workers in Malaysia using standard commercial kits that detect anti-Toxoplasma IgG and IgM antibodies. The results showed that more than half of the workers had latent infection (53.0\%), indicative of previous exposure to $T$. gondi. The high prevalence of latent $T$. gondii infection among these workers suggests that most of these infections were probably acquired in their home countries, where toxoplasmosis is known to be prevalent [27-29].

This study is the first to report on seroprevalence of T.gondii infections in migrant workers from multiple occupation sectors, unlike previous studies which have only reported on a single working sector at a time, e.g. the plantation sector [21-24]. Seroprevalence in our study was marginally higher (57.4\%) compared to previously reported values from migrant workers in Malaysia of between 5.2 and 46.2\% [21-24]. This high seroprevalence is not surprising as human infection is widely reported, with nearly one-third of the world population exposed to this parasite [2, 30,31]. Toxoplasmosis is not exclusive to marginalized communities, but it may have a greater impact on such communities for the reasons argued below. Studies in Malaysia have reported infections (seroprevalence) in healthy individuals (13.9-30.2\%) [32-34], pregnant women (23.0-31.6\%) [35-38], HIV patients $(21.0-41.2 \%)$ [20, 39-41], newborn babies (2.0\%) [42] and indigenous communities (10.6-37.0\%) $[43,44]$. In Southeast Asia, seroprevalence varies from $<2 \%$ up to $70 \%$ [45]. In high income countries, such as the USA and the UK, it has been estimated that between 10 and $40 \%$ of people are infected [46-48], while in Central and South America and continental Europe prevalence ranges from 50 to $80 \%$ [49].

In the present study, two of the factors considered as intrinsic to the sampled individuals showed highly significant associations with $T$. gondii infection. The first variable was age class, with prevalence being higher among workers older than 45 years (74.3 to $76.9 \%$ ) compared with younger workers (51.4 to $59.2 \%$ ). This is in agreement with previous studies $[44,50-53]$ where infections acquired increased with age [32, 39]. A recent study among the indigenous communities of Malaysia (Orang Asli) showed significantly higher seroprevalence $(P \leq 0.001)$ among those aged 12 years and older $(52.6 \%)$, compared to younger participants (31.2\%) [44]. In the current study, prevalence was very similar in both sexes.

The second significant factor affecting seroprevalence was the migrant workers' countries of origin and thought to be related to behavioural and cultural practices such as unintentional ingestion of oocysts shed in cats' faeces and/or consumption of undercooked or raw contaminated meat $[44,54,55]$. Seroprevalence (by $\operatorname{IgG}$ ) was highest among workers from Nepal (77.8\%), followed by Indonesia (58.3\%), Bangladesh (45.8\%), India (38.5\%) and Myanmar (28.6\%), in agreement with a study in 2008 [24]. The strength of country of origin as a significant explanatory factor of $T$. gondii seroprevalence is most likely due to a combination of dietary habits, behavioural risks, environmental conditions, socioeconomic status and poor personal hygiene practice [24]. High prevalence of infection is common among ethnic groups in Nepal due to their habitual ingestion of minced raw meat or insufficiently cooked meat, both of which may harbour tissue cysts of the parasite [28, 29]. Similarly, in Indonesia, $T$. gondi infection is also considered to be a food-borne disease. Gandahusada (1991) [27] linked infection in Indonesia to the presence of domestic animals and eating raw or partially cooked meat with seroprevalence ranging between $2-63 \%$ in humans, between $35-73 \%$ in cats, $75 \%$ in dogs, between $11-36 \%$ in pigs, between $11-61 \%$ in goats, and less than $10 \%$ in cows. In the present study, all the workers originated from rural areas in their respective countries where infections are highly prevalent especially among poor and deprived communities. In such communities, domestic and feral cats are the most likely sources of environmental contamination, leading to direct infections in humans or indirectly through tissue-cyst bearing domestic animals. Significant correlations between consumption of unboiled water and T. gondii seropositivity have also been noted in a few studies, particularly among disadvantaged and indigenous communities living in rural and remote areas, with toxoplasmosis being considered a water-borne disease in these places [14, 56-58]. Contamination of water reservoirs with cat faeces [56] and collection of water from shallow wells located on farms where infected cats are present $[57,58]$ constitute possible sources of human infection with $T$. gondii oocysts.

We found that infections were significantly higher among workers from the manufacturing sector (76.3\%) compared to workers in other sectors. Rai et al. [29] 
highlighted that the nature of one's occupation increases the risk of acquiring $T$. gondii infection especially for those engaged in agricultural activities. However, the present analysis revealed the lowest prevalence of infection (45.1\%) amongst plantation workers. This latter result may be biased to some extent as working sectors were commonly dominated by a particular nationality. In Malaysia, Nepalese workers dominated the manufacturing sector ( $81.7 \%$ were Nepalese) and the high prevalence of infection in the manufacturing sector (74.2\%) was largely attributable to the Nepalese (74.7\%).

Workers with an employment history of less than one year or newly arrived workers were most frequently infected with $T$. gondii except for those in the domestic sector, indicating that acquisition of infection for most immigrant workers was most likely to be from their country of origin [27-29]. The reason for the increase in prevalence between year 1 and 2 among those in the domestic sector is not clear, but may be related to closer contact with domestic cats, which are commonly kept as pets in Malaysia. The majority of domestic workers in this study lived in their own or rented houses (98.1\%) with pets and/or likely to clean cat litter trays as part of their domestic duties. By contrast, workers in other employment sectors mostly live in hostels where they are not allowed to keep pets.

Toxoplasmosis has been associated with the incidence (and prevalence) of schizophrenia and other human affective and psychotic disorders. Antipsychotic drugs known to be effective in the treatment of schizophrenia also inhibit some parasites, predominantly $T$. gondii $[13,59]$. However, access to health care in general and mental health care in particular, is likely to be very low among poor and marginalized communities, with migrant workers less likely to seek care due to stigmatization and fear of job loss.

\section{Conclusions}

In conclusion, high seroprevalence of $T$. gondii among migrant workers in Peninsular Malaysia was found to be positively and statistically significantly associated with age (> 45 years), nationality (Nepalese), employment sector (manufacturing) and shorter duration of residence in Malaysia (with the exception of domestic workers, in whom the converse association was shown). Therefore, our results call for the public health authorities in Malaysia to include a health education programme not only specifically for migrant workers (who have pivotally fueled the Malaysian economy) but also among the general public. This will help to increase public awareness of toxoplasmosis and especially about the importance of cats and the consumption of contaminated meat and water as major potential sources of infection $[14,15]$.

\section{Acknowledgements}

The authors are very grateful to all volunteers from the participating companies and agencies, and the Ministry of Health, Malaysia. Special thanks also go to all medical staff and nurses from University Malaya Medical Centre (UMMC) and Hospital Universiti Kebangsaan Malaysia (HUKM) for their technical assistance. We also gratefully acknowledge the Rockefeller Foundation for the space and time given at the Bellagio Center engaging with residents from a diverse discipline and professions.

\section{Funding}

This research work was funded by University of Malaya, PPP grant PG040-2014A, Fundamental Research Grant Scheme (FRGS) from Ministry of Higher Education, FP015-2014B and UM/MoHE High Impact Research Grant (UM.C/625/1/HIR/ MOHE/MED/23). The funders had no role in study design, data collection and analysis, decision to publish, or preparation of the manuscript.

\section{Availability of data and materials}

Data supporting the conclusions of this article are included within the article. The datasets generated during and/or analysed during the current study are available from the corresponding author on reasonable request.

\section{Authors' contributions}

NS, SNMZ, YALL, JMB, JWL, FA made substantial contributions to conception and design, acquisition of data, analysis and interpretation of data. NS, SNMZ, YALL, JMB, JWL, MGB, MW, RN, KAA been involved in drafting the manuscript and revising it critically for important intellectual content. All authors agreed to be accountable for all aspects of the work in ensuring that questions related to the accuracy or integrity of any part of the work are appropriately investigated and resolved. All authors read and approved the final manuscript.

\section{Competing interests}

The authors declare that they have no competing interests.

\section{Consent for publication}

Written informed consent was obtained from all participants.

\section{Ethics approval and consent to participate}

The study procedure was approved by the ethics committee of the University Malaya Medical Centre (UMMC), Malaysia, prior to commencement of the study (Reference number: MECID NO: 20143-40). Written informed consent was obtained from all participants.

\section{Publisher's Note}

Springer Nature remains neutral with regard to jurisdictional claims in published maps and institutional affiliations.

\section{Author details}

${ }^{1}$ Institute of Biological Science, Faculty of Science, University of Malaya, Kuala Lumpur, Malaysia. ${ }^{2}$ Department of Parasitology, Faculty of Medicine, University of Malaya, Kuala Lumpur, Malaysia. ${ }^{3}$ Primary Care Medicine, Faculty of Medicine, UiTM Sungai Buloh Campus, Sungai Buloh, Selangor, Malaysia.

${ }^{4}$ School of Life Sciences, University of Nottingham, University Park,

Nottingham NG7 2RD, UK. ${ }^{5}$ Department of Infectious Disease Epidemiology and London Centre for Neglected Tropical Disease Research, School of Public Health, St Mary's Campus, Imperial College London, London W2 1PG, UK. ${ }^{6}$ Department of Pathobiology and Population Sciences and London Centre for Neglected Tropical Disease Research, Royal Veterinary College, Hawkshead Lane, Hatfield, Hertfordshire AL97TA, UK. School of Biological Sciences, Royal Holloway, University of London, Egham, Surrey TW20 OEX, UK. ${ }^{8}$ Institute for Research Molecular Medicine, University of Science Malaysia, Gelugor, Penang, Malaysia. ${ }^{9}$ MAHSA University, Jalan Elmu off Jalan University, Kuala Lumpur, Malaysia.

Received: 31 October 2016 Accepted: 2 May 2017

Published online: 15 May 2017

\section{References}

1. Feldman HA. Toxoplasmosis: An overview. Bull NY Acad Med. 1974;50:110-27.

2. Montoya JG, Liesenfeld O. Toxoplasmosis. Lancet. 2004;363:1965-76.

3. Hill DE, Chirukandoth S, Dubey JP. Biology and epidemiology of Toxoplasma gondii in man and animals. Anim Health Res Rev. 2005;6:41-61. 
4. Jacobs LJ. Toxoplasma gondii: Parasitology and transmission. Bull NY Acad Med. 1974:50:128-45.

5. Abu Bakar A, Khairul Anuar A. Mat Ludin, Rahmah N. Survey of meat samples for Toxoplasma gondii in Northern Peninsular Malaysia. Diagnosa. 1992;6:700-4.

6. Kolbekova' P, Kourbatova E, Novotna' M, Kodym P, Flegr J. New and old risk-factors for Toxoplasma gondii infection: prospective cross-sectional study among military personnel in the Czech Republic. Clin Microbiol Infect. 2007:13:1012-17.

7. Ferguson DJ. Identification of faecal transmission of Toxoplasma gondii: Small science, large characters. Int J Parasitol. 2009;39:871-75.

8. Jones JL, Dargelas V, Roberts J, Press C, Remington JS, Montoya JG. Risk factors for Toxoplasma gondii infection in the United States. Clin Infect Dis. 2009;49:878-84

9. Petersen E, Vesco G, Villari S, Buffolano W. What do we know about risk factors for infection in humans with Toxoplasma gondii and how can we prevent infections? Zoonoses Public Hlth. 2010;57:8-17.

10. Husni OM, Bowman DD, Khairul Anuar A, Rahmah N. Evaluation of strategies to reduce the risk of congenital toxoplasmosis. J Eukaryot Microbiol. 1994;41:155.

11. Remington JS, Klein JO. Infectious diseases of the fetus and newborn infant. Philadelphia: Saunders. Xiv; 2001

12. Hanifa, Khairul Anuar A, Rahmah N. Cerebral toxoplasmosis in AIDS: A case report and literature review. Trop Biomed. 1996:13:29-33.

13. Yolken RH, Dickerson FB, Torrey EF. Toxoplasma and schizophrenia. Parasite Immunol. 2009;31(11):706-15.

14. Torrey EF, Yolken RH. Toxoplasma oocysts as a public health problem. Trends Parasitol. 2013;29(8):380-4.

15. Torrey EF, Simmons W, Yolken RH. Is childhood cat ownership a risk factor for schizophrenia later in life? Schizophr Res. 2015;165(1):1-2.

16. Alvarado-Esquivel C, Sifuentes-Álvarez A, Narro-Duarte SG, Estrada-Martínez S, Díaz-García JH, Liesenfeld O, et al. Seroepidemiology of Toxoplasma gondii infection in pregnant women in a public hospital in northern Mexico. BMC Infect Dis. 2006;6:113

17. Binnicker MJ, Jespersen DJ, Harring JA. Multiplex detection of IgM and lgG class antibodies to Toxoplasma gondii, rubella virus, and cytomegalovirus using a novel multiplex floww immunoassay. Clin Vaccine Immunol. 2010;17:1734-38

18. Mwambe B, Mshana SE, Kidenya BR, Massinde AN, Mazigo HD, Micheal D, et al. Sero-prevalence and factors associated with Toxoplasma gondii infection among pregnant women attending antenatal care in Mwanza. Tanzania Parasit Vectors. 2013;6:222

19. Yahaya N. Review of toxoplasmosis in Malaysia. Southeast Asian J Trop Med Public Health. 1991:22:102-6.

20. Nissapatorn $\mathrm{V}$, Kamarulzaman A, Init I, Tan LH, Rohela M, Norliza A, et al. Seroepidemiology of toxoplasmosis among HIV infected patients and healthy blood donors. Med J Malaysia. 2002;57:304-10.

21. Chan BTE, Amal RN, Noor Hayati MI. Toxoplasmosis among Indonesian Migrant Workers in Malaysia. Malays J Med Sci. 2009;5:31-7.

22. Chan BTE, Amal RN, Noor Hayati MI, Hideto K, Anisah N, Norhayati M. Comparative study of seroprevalence of toxoplasmosis between local workers and migrant workers in Malaysia. Arch Med Sci. 2009;5:255-8.

23. Amal RN, Chan BTE, Noor Hayati MI, Kino H, Anisah N, Norhayati M, et al. Seroprevalence of toxoplasmosis: comparative study between migrant workers from the Indian subcontinent and local Malaysian workers. Iraqi J Med. 2008:4:9-15.

24. Chan BTE, Amal RN, Noor Hayati MI, Kino H, Anisah N, Norhayati M, et al. Seroprevalence of toxoplasmosis among migrant workers from different Asian countries working in Malaysia. Southeast Asian J Trop Med Public Health. 2008:39:9-13.

25. Norhayati M, Fatmah MS, Yusof S, Edariah AB. Intestinal parasitic infections in man: a review. Med J Malaysia. 2003;58:296-305

26. Rohlf FJ, Sokal RR. Statistical Tables 3rd edition. San Francisco, USA: W.H. Freeman and Company; 1995.

27. Gandahusada S. Study on the prevalence of toxoplasmosis in Indonesia: a review. Southeast Asian J Trop Med Public Health. 1991;22:93-8.

28. Rai SK, Shibata H, Sumi K, Kubota K, Hirai K, Matsuoka A, et al. Seroepidemiologica study of toxoplasmosis in two different geographical areas in Nepal. Southeast Asian J Trop Med Public Health. 1994:25:479-84.

29. Rai SK, Matsumura T, Ono K, Abe A, Hirai K, et al. High Toxoplasma seroprevalence associated with meat eating habits of locals in Nepal. Asia Pac J Public Health. 1999;11:89-93.
30. Dubey JP, Beattie CP. Toxoplasmosis of animals and man. Boca Raton: CRC Press; 1988. p. 220

31. Dubey JP. Toxoplasmosis of animals and humans. Boca Raton: CRC Press; 2010. p. 313.

32. Tan DSK, Zaman V. Toxoplasma antibody survey in West Malaysia. Med J Malaysia. 1973:17:188-91.

33. Thomas V, Sinniah B, Yap PL. Prevalence of antibodies including IgM to Toxoplasma gondii in Malaysia. Southeast Asian J Trop Med Public Health. 1980;11:119-25.

34. Sinniah B, Thomas V, Yap PL. Toxoplasmosis in West Malaysian population. Trop Biomed. 1984;1:81.

35. Cheah WC, Fah CS, Fook CW. Pattern of toxoplasma antibodies in Malaysian pregnant women. Med J Malaya. 1975:29:275-9.

36. Tan SDK, Cheah W, Sukumaran KD, Stern H. The "TORCHES" (congenital toxoplasmosis) programme 1 in women of child-bearing age. Singapore Med J. 1976;17:207-10

37. Khairul Anuar A, Afifi AB, Dighe VC, Rosiani AMM. Toxoplasma antibody in pregnant women in northern Peninsular Malaysia. Diagnosis. 1991;5:18-23.

38. Ravichandran J, Rahmah N, Kamaruzzaman A, Khairul Anuar A. Toxoplasma gondii antibodies among Malaysian pregnant women: A hospital-based study. Biomed Res. 1998;1:25-8.

39. Nissapatorn V, Lee CKC, Cho SM, Rohela M, Khairul Anuar A, et al. Toxoplasmosis in HIV/AIDS patients in Malaysia. Southeast Asian J Trop Med Public Health. 2003;34:80-5.

40. Nissapatorn V, Lee CKC, Khairul AA. Seroprevalence of toxoplasmosis among AIDS patients in Hospital Kuala Lumpur, 2001. Singapore Med J. 2003:44:194-6.

41. Nissapatorn V, Lee C, Quek KF, Khairul AA. AIDS-related opportunistic infections in Hospital Kuala Lumpur. Jpn J Infect Dis. 2003:55:187-92.

42. Tan DSK, Mak JW. The role of toxoplasmosis in congenital disease in Malaysia. Southeast Asian J Trop Med Public Health. 1985;16:88-92.

43. Lokman HS, Radzan T, Nazma M. Distribution of anti-Toxoplasma gondii antibodies among Orang Asli (Aborigines) in peninsular Malaysia. Southeast Asian J Trop Med Public Health. 1994;25:485-9.

44. Ngui R, Lim YAL, Amir NFH, Nissapatorn V, Mahmud R. Seroprevalence and sources of toxoplasmosis among Orang Asli (indigenous) communities in Peninsular Malaysia. Am J Trop Med Hyg. 2011;85:660-6.

45. Nissapatorn V. Toxoplasmosis: A silent threat in Southeast Asia. Res J Parasitol. 2007;2:1-12

46. Bhatia VN, Meenakshi K, Aggarwal SC. Toxoplasmosis in South India, a serological study. Indian J Med Res. 1974;62:1818-25.

47. Dubey JP. Toxoplasmosis. J Am Vet Med Assoc. 1994;205:1593-8.

48. Sukthana Y. Toxoplasmosis: beyond animals to humans. Trends Parasitol. 2006;22:137-42.

49. Jones $J$, Kruszon-Moran D, Wilson M. Toxoplasma gondii prevalence, United States [letter]. Emerg Infect Dis. 2007:13:656-7.

50. Tenter AM, Heckeroth AR, Weiss LM. Toxoplasma gondii: from animals to humans. Int J Parasitol. 2000;30:1217-58.

51. Nissapatorn $V$, Abdullah KA. Review on human toxoplasmosis in Malaysia: the past, present and prospective future. Southeast Asian J Trop Med Public Health. 2004;35:24-30

52. Sobral CA, Amendoeira MR, Teva A, Patel BN, Klein CH. Seroprevalence of infection with Toxoplasma gondii in indigenous Brazilian populations. Am J Trop Med Hyg. 2005:72:37-41.

53. Abu-Madi MA, Al-Molawi N, Behnke JM. Seroprevalence and epidemiological correlates of Toxoplasma gondii infections among patients referred for hospital-based serological testing in Doha, Qatar. Parasit Vectors. 2008;1:39.

54. Apt W, Thiermann E, Niedmann G, Pasmanik S. Toxoplasmosis. Santiago: Universidad de Chile; 1973

55. Amendoeira MRR, Costa T, Spalding SM. Toxoplasma gondii Nicolle \& Manceaux, 1909 (Apicomplexa: Sarcocystidae) e atoxoplasmose. Revista Souza Marques. 1999;1:15-35.

56. de Moura L, Bahia-Oliveira LM, Wada MY, Jones JL, Tuboi SH, Carmo EH, et al. Waterborne toxoplasmosis, Brazil, from field to gene. Emerg Infect Dis. 2006:12:326-9.

57. Sroka J, Wójcik-Fatla A, Dutkiewicz J. Occurrence of Toxoplasma gondii in water from wells located on farms. Ann Agric Environ Med. 2006;13:169-75

58. Sroka J, Wojcik-Fatla A, Szymanska J, Dutkiewicz J, Zajac V, Zwolinski J. The occurrence of Toxoplasma gondii infection in people and animals from 
rural environment of Lublin region - estimate of potential role of water as a source of infection. Ann Agric Environ Med. 2010;17:125-32.

59. Webster JP, Lamberton PHL, Donnelly CA, Torrey EF. Parasites as causative agents of human affective disorders? The impact of anti-psychotic,

mood-stabilizer and anti-parasite medication on Toxoplasma gondii's ability to alter host behaviour. Proc R Soc B (Biol Sci). 2006;273(1589):1023-30.

Submit your next manuscript to BioMed Central and we will help you at every step:

- We accept pre-submission inquiries

- Our selector tool helps you to find the most relevant journal

- We provide round the clock customer support

- Convenient online submission

- Thorough peer review

- Inclusion in PubMed and all major indexing services

- Maximum visibility for your research

Submit your manuscript at www.biomedcentral.com/submit 